\title{
Association between household food insecurity and annual health care costs
}

\author{
Valerie Tarasuk PhD, Joyce Cheng MSc, Claire de Oliveira PhD, Naomi Dachner MSc, Craig Gundersen PhD, \\ Paul Kurdyak MD PhD
}

CMAJ Podcasts: author interview at soundcloud.com/cmajpodcasts/150234-res

See also www.cmaj.ca/lookup/doi/10.1503/cmaj.150644

\begin{abstract}
Background: Household food insecurity, a measure of income-related problems of food access, is growing in Canada and is tightly linked to poorer health status. We examined the association between household food insecurity status and annual health care costs.
\end{abstract}

Methods: We obtained data for 67033 people aged 18-64 years in Ontario who participated in the Canadian Community Health Survey in $2005,2007 / 08$ or $2009 / 10$ to assess their household food insecurity status in the 12 months before the survey interview. We linked these data with administrative health care data to determine individuals' direct health care costs during the same 12-month period.

Results: Total health care costs and mean costs for inpatient hospital care, emergency department visits, physician services, same-day surgeries, home care services and prescription drugs covered by the Ontario Drug Benefit Program rose systematically with increasing severity of household food insecurity. Compared with total annual health care costs in food-secure households, adjusted annual costs were $16 \%$ (\$235) higher in households with marginal food insecurity $(95 \%$ confidence interval $[\mathrm{Cl}]$ $10 \%-23 \%$ [\$141-\$334]), 32\% (\$455) higher in households with moderate food insecurity (95\% Cl 25\%-39\% [\$361-\$553]) and 76\% (\$1092) higher in households with severe food insecurity (95\% Cl 65\%-88\% [\$934-\$1260]). When costs of prescription drugs covered by the Ontario Drug Benefit Program were included, the adjusted annual costs were $23 \%$ higher in households with marginal food insecurity $(95 \% \mathrm{Cl} 16 \%-31 \%), 49 \%$ higher in those with moderate food insecurity $(95 \% \mathrm{Cl} 41 \%-$ $57 \%$ ) and $121 \%$ higher in those with severe food insecurity $(95 \% \mathrm{Cl} 107 \%-136 \%)$.

Interpretation: Household food insecurity was a robust predictor of health care utilization and costs incurred by working-age adults, independent of other social determinants of health. Policy interventions at the provincial or federal level designed to reduce household food insecurity could offset considerable public expenditures in health care.
I ncome-related problems of food access, variously termed "food poverty" or "food insecurity," are increasingly recognized as serious social and public health problems in many affluent nations. In 2012, 12.6\% of Canadian households were affected by some degree of food insecurity; this is the highest rate observed since national monitoring began in $2007 .{ }^{1}$

Problems of food insecurity are intertwined with household resource constraints, but food insecurity is nonetheless a strong predictor of poorer physical and mental health, independent of other well-established social determinants of health. Among children, food insecurity has been linked to poorer health status ${ }^{2-6}$ and the development of a variety of chronic health conditions, including asthma and depression. ${ }^{7,8}$ Among adults, it has been associated with multiple indicators of chronic disease and poorer health. ${ }^{9-11}$ The association between food insecurity and health appears to be a gradient, with adults in more severely food-insecure households more likely to report chronic health conditions ${ }^{12-14}$ and to receive diagnoses of multiple conditions. ${ }^{11}$ Household food insecurity has been shown to diminish adults' functional health, ${ }^{15}$ pose barriers to self-care for those with chronic conditions, ${ }^{16-18}$ increase the probability that they will become high-cost users of health care ${ }^{19}$ and heighten the risk of negative disease outcomes. ${ }^{17,20}$

Our understanding of the association between household food insecurity and health is largely
Competing interests: None declared.

This article has been peer reviewed.

Accepted: June 26, 2015

Online: Aug. 10, 2015

Correspondence to:

Valerie Tarasuk, valerie.

tarasuk@utoronto.ca

CMAJ 2015. DOI:10.1503/ cmaj.150234 
based on analyses of population-based surveys with self-reported measures of health. Few studies have drawn on clinical measures of health status ${ }^{10,20-23}$ or health services data, ${ }^{16,19,24,25}$ and there has been no examination of the total burden of ill health associated with food insecurity or the implications for health care costs.

In Canada, where the provision of health care is universal and food insecurity appears tightly linked to health status, understanding the health consequences and related health care costs is critical for charting program and policy directions to address household food insecurity. Using linked survey and administrative health care data from the province of Ontario, we examined the association between adults' household food security status over a 12-month period and their direct health care costs during this period, from the perspective of the payer, the Ontario Ministry of Health and Long-term Care.

\section{Methods}

\section{Data sources}

Data were drawn from Canadian Community Health Survey conducted in 2005, 2007/08 and $2009 / 10 .^{26-29}$ This survey is a repeated crosssectional survey designed to be representative of $98 \%$ of the Canadian population aged 12 and over; individuals living on First Nation reserves, those in institutions and personnel in the Canadian Armed forces are excluded. Once a household is identified as part of the sample, one household member is selected based on various sampling probabilities related to age and household composition.

We linked Canadian Community Health Survey data for Ontario to de-identified administrative health care data housed at the Institute for Clinical Evaluative Sciences. The administrative databases included the Canadian Institute for Health Information Discharge Abstract Database and Same Day Surgery Database, the Ontario Mental Health Reporting System, the National Ambulatory Care Reporting System, the Continuing Care Reporting System, Ontario Health Insurance Plan (OHIP) claims database, the Ontario Drug Benefit claims database, the Home Care Database, the National Rehabilitation Reporting System, the Continuing Care Reporting System and the Assisted Devices Program Database. These datasets were linked with the use of unique encoded identifiers and analyzed at the Institute for Clinical Evaluative Sciences.

\section{Study population}

Our initial linked sample comprised 67947 participants in the Canadian Community Health Survey who were aged 18-64 years, were living in Ontario and had a valid Ontario health insurance number during the 12 months before the survey interview. We excluded 580 individuals who had missing data on food security status and 334 with missing data on sociodemographic variables; this left 67033 individuals in the final analytic sample.

To minimize loss of sample due to missing data on income (a problem affecting $21 \%$ of respondents), we derived neighbourhood-level income quintiles by linking 2006 census data to the patients' residential postal code data. Statistics Canada has adjusted income for household size and community size such that each community would be expected to have $20 \%$ of its population in each income quintile. This ecological proxy methodology has been found to estimate household income quintiles reliably. ${ }^{30}$

\section{Measures}

Household food security status and sociodemographic characteristics were derived from the Canadian Community Health Survey. We assessed household food insecurity during the 12 months before the survey using an 18-item scale (Appendix 1, available at www.cmaj.ca/lookup/suppl/ doi:10.1503/cmaj.150234/-/DC1) also used to monitor food insecurity in the United States. ${ }^{31,32}$ Health Canada's coding method was applied to define moderate and severe food insecurity. ${ }^{32}$ Survey participants with no affirmative responses were considered "food secure." Those with one affirmative response were considered "marginally food insecure," given evidence of heightened vulnerability with even a single affirmative response on this scale. ${ }^{11,12,33-35}$ (The coding applied to determine household food security status is described in Appendix 2, available at www.cmaj.ca/lookup/ suppl/doi:10.1503/cmaj.150234/-/DC1).

To calculate individual-level health care costs for the 12-month period before the survey interview, we linked utilization data from administrative health care databases with individual provider and corporate cost information collected by the Ontario Ministry of Health and Long-Term Care. ${ }^{36}$ The total cost of health care included costs for acute and psychiatric inpatient care, emergency department visits, physician services and outpatient care, same-day surgeries, home care, claims for outpatient prescription drugs covered under the Ontario Drug Benefit Program and other (e.g., rehabilitation, complex continuing care, long-term care, assisted devices). We adjusted all costs to 2012 Canadian dollars. ${ }^{36}$

\section{Statistical analysis}

We describe sample characteristics using means and proportions. Linear trend tests were performed to examine the association between each covariate 
and food security status; analysis of variance was used for continuous variables and the CochranArmitage test for categorical variables. Linear trend tests were conducted to analyze the association between different types of health care costs and household food insecurity status.

Two-part regression models ${ }^{37}$ were used to determine the association between household food insecurity and the costs associated with each participant's health care utilization. First, we modelled the odds of incurring any expenditure using logistic regression analysis. We then modelled the level of expenditure, conditional on incurring any expenditure, using ordinary leastsquares regression with a logged dependent variable (based on the Park test, which showed that the residuals were normally distributed and homoscedastic). ${ }^{38} \mathrm{We}$ adjusted the models for age, sex and sociodemographic characteristics identified through prior research as significant predictors of household food insecurity ${ }^{11}$ and health care costs. These variables included education level, neighbourhood income quintile, number of children and adults living in the household, and home ownership. We used the Duan smearing estimator to retransform the ordinary least-squares regression estimates to the original units in dollars. ${ }^{39}$

We ran the 2-part regression models both with and without the inclusion of the Ontario Drug Benefit claims in total health care costs. We did this because, unlike the other cost categories considered, this public drug program is available only to select population subgroups. ${ }^{40}$ Among adults under 65 years of age, eligibility for drug benefits is linked to eligibility for social assistance, which in turn is known to be associated with high risk of food insecurity, specifically more severe food insecurity. ${ }^{1}$ Thus, Ontario Drug Benefit costs are potential confounders of food insecurity that would increase the probability of finding significant differences by food security status.

Table 1: Characteristics of 67033 people aged 16-64 who participated in the Canadian Community Health Survey in 2005, 2007/08 or 2009/10, by household food security status

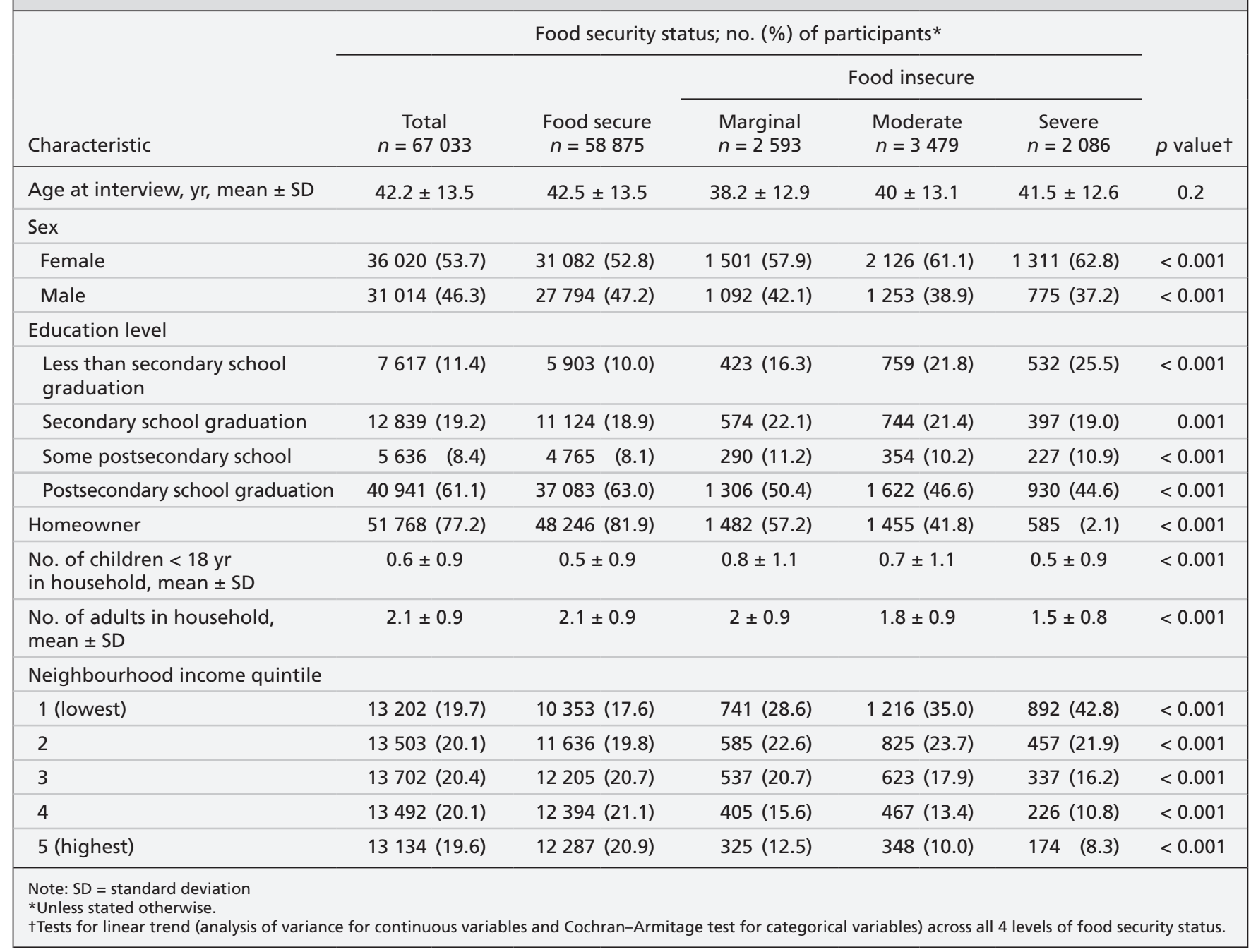


We conducted a sensitivity analysis to examine the impact of using neighbourhood-level income quintiles rather than reported household incomes in the 2-part regression models. Models that included only participants who reported household income were run with income included as a continuous variable.

All analyses were conducted with the use of SAS statistical software, version 9.2. The significance level was set at $p<0.05$.

\section{Results}

The mean age of participants in the study sample was 42.2 (standard deviation \pm 13.5 ) years, and $53.7 \%$ were female (Table 1). With respect to food insecurity status, $3.9 \%$ lived in marginally, $5.2 \%$ in moderately and $3.1 \%$ in severely food insecure households. When stratified by household food insecurity status, the participants differed significantly in age, education level, home ownership, household composition and household income (Table 1).

Mean individual-level health care costs rose systematically with increasing severity of household food insecurity (Table 2). This gradient was statistically significant for costs arising from every type of health care services except "other" costs (i.e., rehabilitation, complex continuing care, long-term care and assisted devices).

Overall, 89.2\% (59 817) of the 67033 participants used heath care (excluding outpatient prescription drugs covered under the Ontario Drug Benefit Program) in the 12-month period before their survey interview (Table 3). After adjusting for sociodemographic variables, we found that individ- uals who were in severely food insecure households had 1.71 times the odds of using health care services (95\% confidence interval [CI] 1.44-2.04) than those in food secure households; individuals in moderately food insecure households had 1.33 times the odds of using health care $(95 \%$ CI 1.18 1.50). Participants in marginally food insecure households did not have significantly higher odds of using health care (odds ratio 1.13, 95\% CI 0.991.29) than those in food secure households.

Among health care users, total health care costs increased significantly with the level of food insecurity (Table 3 ). Compared with total annual costs in food-secure households, adjusted annual costs were, on average, 16\% (\$235) higher in households with marginal food insecurity (95\% CI $10 \%-23 \%$ [ $\$ 141-\$ 334]), 32 \%$ (\$455) higher in households with moderate food insecurity (95\% CI 25\%-39\% [\$361-\$553]) and $76 \%$ (\$1092) higher in households with severe food insecurity (95\% CI 65\%-88\% [\$934\$1260]).

When we repeated these analyses to include prescription drug costs, we found that all 3 levels of food insecurity were associated with significantly increased odds of using health care services (Appendix 3, Table A, available at www.cmaj. ca/lookup/suppl/doi:10.1503/cmaj.150234/-/DC1) and even greater increases in total health care costs compared with individuals in food-secure households. Adjusted annual health care costs were $23 \%$ higher in households with marginal food insecurity (95\% CI 16\%-31\%), 49\% higher in those with moderate food insecurity $(95 \%$ CI $41 \%-57 \%$ ) and $121 \%$ higher in households with severe food insecurity (95\% CI 107\%-136\%).

Table 2: Mean individual-level health care costs for the 12-month period before the survey interview, by household food security status

\begin{tabular}{|c|c|c|c|c|c|c|}
\hline \multirow[b]{3}{*}{ Health care service } & \multicolumn{5}{|c|}{ Food security status; adjusted cost, ${ }^{*} \$$, mean \pm SD } & \multirow[b]{3}{*}{$p$ valuet } \\
\hline & \multirow[b]{2}{*}{$\begin{array}{c}\text { Total } \\
n=59869\end{array}$} & \multirow[b]{2}{*}{$\begin{array}{c}\text { Food secure } \\
n=52440\end{array}$} & \multicolumn{3}{|c|}{ Food insecure } & \\
\hline & & & $\begin{array}{l}\text { Marginal } \\
n=2321\end{array}$ & $\begin{array}{c}\text { Moderate } \\
n=3172\end{array}$ & $\begin{array}{c}\text { Severe } \\
n=1936\end{array}$ & \\
\hline Inpatient care & $500 \pm 3927$ & $461 \pm 3897$ & $604 \pm 3366$ & $730 \pm 4251$ & $1063 \pm 4673$ & $<0.001$ \\
\hline Emergency department visits & $116 \pm 355$ & $105 \pm 321$ & $153 \pm 381$ & $181 \pm 436$ & $282 \pm 761$ & $<0.001$ \\
\hline Physician services & $718 \pm 1406$ & $688 \pm 1365$ & $765 \pm 1296$ & $905 \pm 1530$ & $1165 \pm 2144$ & $<0.001$ \\
\hline Same-day surgery & $105 \pm 499$ & $102 \pm 489$ & $118 \pm 537$ & $118 \pm 570$ & $139 \pm 606$ & 0.003 \\
\hline Home care & $75 \pm 1066$ & $65 \pm 1061$ & $147 \pm 1287$ & $131 \pm 939$ & $175 \pm 1101$ & $<0.001$ \\
\hline Ontario Drug Benefit claims & $160 \pm 1296$ & $99 \pm 1129$ & $305 \pm 1393$ & $587 \pm 2411$ & $943 \pm 2120$ & $<0.001$ \\
\hline Other $¥$ & $93 \pm 2312$ & $88 \pm 2290$ & $70 \pm 1483$ & $155 \pm 2642$ & $164 \pm 3014$ & 0.09 \\
\hline Total & $1768 \pm 6589$ & $1608 \pm 6414$ & $2161 \pm 6235$ & $2806 \pm 7923$ & $3930 \pm 8455$ & $<0.001$ \\
\hline
\end{tabular}


When these analyses were repeated to include only participants who reported household income, with household income used in the models instead of neighbourhood income quintile, the associations between food insecurity status and health care utilization and costs were slightly stronger than in the main analyses (Appendix 3, Table B).

\section{Interpretation}

Our study showed that household food insecurity status was a robust predictor of health care utilization and costs incurred by working-age adults in Ontario, independent of other well-established social determinants of health. The observed effect of household food insecurity on health care expenditures was free of selection issues because our study occurred in the context of a universal health care system. Even when we excluded costs for prescription drugs covered by the Ontario Drug Benefits plan, because the plan is available only to a subset of the population, we still found a highly significant effect of food insecurity on health care spending.

To date, no provincial or federal intervention has been introduced with the explicit goal of reduc-

Table 3: Results of 2-part regression model predicting health care utilization and total health care costs over a 12-month period

\begin{tabular}{|c|c|c|c|c|}
\hline \multirow[b]{2}{*}{ Variable } & \multicolumn{2}{|c|}{$\begin{array}{l}\text { Odds of health care expenditure* } \\
\qquad n=67033\end{array}$} & \multicolumn{2}{|c|}{$\begin{array}{l}\text { Total health care costs per persont } \\
\qquad n=59817\end{array}$} \\
\hline & $\begin{array}{l}\text { Unadjusted } \\
\text { OR }(95 \% \mathrm{Cl})\end{array}$ & $\begin{array}{l}\text { Adjusted } ¥ \\
\text { OR }(95 \% \mathrm{Cl})\end{array}$ & $\begin{array}{c}\text { Unadjusted } \\
\text { mean, } \$(95 \% \mathrm{Cl})\end{array}$ & $\begin{array}{c}\text { Adjusted } \neq \\
\text { mean, } \$(95 \% \mathrm{Cl})\end{array}$ \\
\hline \multicolumn{5}{|l|}{ Food insecurity status } \\
\hline Food secure & 1.00 (ref) & 1.00 (ref) & $1516(1498-1534)$ & $1438(1421-1455)$ \\
\hline Marginally food insecure & $1.03(0.90-1.17)$ & $1.13(0.99-1.29)$ & 1748 (1647-1849) & $1673(1579-1767)$ \\
\hline Moderately food insecure & $1.21(1.08-1.36)$ & $1.33(1.18-1.50)$ & 2143 (2037-2249) & $1892(1800-1985)$ \\
\hline Severely food insecure & $1.54(1.30-1.81)$ & $1.71(1.44-2.04)$ & $3078(2883-3273)$ & $2529(2370-2688)$ \\
\hline Age§ & $1.02(1.02-1.02)$ & $1.02(1.02-1.02)$ & $1542(1525-1559)$ & $1494(1478-1511)$ \\
\hline \multicolumn{5}{|l|}{ Sex } \\
\hline Male & 1.00 (ref) & 1.00 (ref) & $1216(1196-1237)$ & $1128(1109-1146)$ \\
\hline Female & $3.00(2.84-3.16)$ & $2.98(2.83-3.15)$ & $2011(1981-2041)$ & $1855(1828-1882)$ \\
\hline \multicolumn{5}{|l|}{ Education level } \\
\hline Less than secondary school graduation & $0.96(0.88-1.03)$ & $1.02(0.94-1.11)$ & 1989 (1922-2057) & $1678(1622-1734)$ \\
\hline Secondary school graduation & $0.87(0.81-0.92)$ & $0.94(0.88-1.01)$ & $1521(1481-1561)$ & $1460(1423-1497)$ \\
\hline Some postsecondary school & $0.90(0.83-0.98)$ & $1.08(0.98-1.18)$ & $1382(1327-1436)$ & $1446(1391-1502)$ \\
\hline Postsecondary school graduation & 1.00 (ref) & 1.00 (ref) & $1585(1562-1609)$ & $1480(1459-1500)$ \\
\hline \multicolumn{5}{|l|}{ Homeowner } \\
\hline Yes & 1.00 (ref) & 1.00 (ref) & $1523(1504-1543)$ & $1447(1428-1465)$ \\
\hline No & $0.74(0.70-0.78)$ & $0.77(0.72-0.82)$ & 1869 (1824-1915) & $1673(1630-1717)$ \\
\hline No. of children $<18 \mathrm{yr}$ in household & $1.08(1.05-1.10)$ & $1.10(1.07-1.13)$ & $1600(1581-1618)$ & $1494(1478-1511)$ \\
\hline No. of adults in household & $0.96(0.93-0.98)$ & $1.05(1.0-1.08)$ & $1586(1568-1604)$ & $1494(1478-1511)$ \\
\hline \multicolumn{5}{|l|}{ Neighbourhood income quintile } \\
\hline 1 (lowest) & 1.00 (ref) & 1.00 (ref) & 1759 (1714-1805) & $1526(1487-1566)$ \\
\hline 2 & $1.05(0.97-1.13)$ & $1.01(0.93-1.09)$ & $1613(1572-1654)$ & 1485 (1449-1522) \\
\hline 3 & $1.07(0.99-1.15)$ & $1.00(0.93-1.09)$ & $1558(1519-1598)$ & $1473(1438-1509)$ \\
\hline 4 & $1.18(1.09-1.27)$ & $1.09(1.01-1.18)$ & $1553(1513-1592)$ & $1495(1459-1532)$ \\
\hline 5 (highest) & $1.20(1.11-1.30)$ & $1.11(1.03-1.21)$ & 1553 (1513-1592) & $1493(1456-1530)$ \\
\hline \multicolumn{5}{|c|}{$\begin{array}{l}\text { Note: } \mathrm{Cl}=\text { confidence interval, } \mathrm{OR}=\text { odds ratio, ref }=\text { reference group. } \\
\text { *Part } 1: \text { logistic regression analysis was used to estimate the odds of incurring any v. no health care cost over the } 12 \text {-month period, excluding Ontario Drug } \\
\text { Benefit costs. } \\
+ \text { Part 2: ordinary least-squares regression analysis was used to determine the total health care costs per person associated with each variable, conditional on } \\
\text { incurring any cost during the same } 12 \text {-month period. Costs were adjusted to } 2012 \text { Canadian dollars. Model estimates have been retransformed to provide the } \\
\text { predicted cost at the mean value for each variable. } \\
\text { †Adjusted for all other variables in the table. } \\
\text { §Odds ratios are per year increase in age. }\end{array}$} \\
\hline
\end{tabular}


ing household food insecurity, but our study findings suggest that such intervention would offset considerable public expenditures on health care. Some have argued that health care providers should screen patients for food insecurity and then assist them to access additional supports, such as the publicly funded food assistance programs available in the US. ${ }^{10,41}$ However, in Canada, there are no publicly funded programs designed to prevent or alleviate food insecurity and the existing ad hoc community-based food charities and other food programs lack the capacity to alter household food insecurity. ${ }^{42-45}$ Thus, health care providers have little chance of altering patients' circumstances through referrals. A more upstream approach is required, with policy interventions aimed at reducing the prevalence and severity of food insecurity. Relatively modest increments in income have been found to lessen food insecurity among low-income families, ${ }^{46-48}$ and the lower rate of food insecurity among Canadian seniors has been attributed to the guaranteed annual incomes provided to them. ${ }^{49,50}$

Our findings are consistent with reports of poorer health and increased probability of diagnoses of chronic disease, ${ }^{10,11,13}$ poorer disease management ${ }^{16-18}$ and increased health care costs ${ }^{5}$ associated with household food insecurity, with the evidence of a graded relation between severity of food insecurity and adults' health status. ${ }^{11,14,35}$ The extreme levels of material deprivation associated with household food insecurity, and severe food insecurity in particular, have been associated with extensive dietary compromise, ${ }^{51-53}$ higher levels of stress $^{35,54}$ and compromises across a broad spectrum of basic needs, ${ }^{33,54,55}$ all of which diminish individuals' abilities to manage health problems and potentially increase the need for health care. Yet, empirical examinations of the resultant health care costs have been limited by the paucity of datasets, including both a validated measure of household food insecurity and objective measures of health care utilization. ${ }^{15}$

\section{Limitations}

Our study was well designed to capture health care costs borne by the provincial government, but we did not have data on out-of-pocket expenditures or on health care costs covered by private insurance plans or employee benefit programs. Prior research suggests that out-of-pocket expenditures on health care are inversely associated with household food insecurity, ${ }^{55-57}$ because such expenditures are often foregone in the context of competing financial demands for scarce resources. In addition, although some individuals in households reliant on employment incomes might have received supplementary drug coverage through their employer, the employment conditions associated with food in- security in Canada ${ }^{58}$ suggest that many would not have had such benefits. Had we been able to construct a comprehensive account of individuals' health care costs, we hypothesize that health care expenditures would have risen disproportionately among food-secure adults owing to the inclusion of prescription drug benefits. As a consequence, observed differences associated with household food insecurity status would have been attenuated, but this would not have affected the sharp gradient in public expenditures on health care related to food insecurity status.

The strong gradient in health care costs associated with increasing severity of household food insecurity suggests a causal relation between food insecurity and health care utilization, but more research is needed to confirm the direction of the effects, recognizing the possibility of a bidirectional association between adults' health and their household food security status. ${ }^{59-61}$ Further research is also needed to elucidate the pathway(s) through which household food insecurity affects adults' health and use of health care, distinguishing costs arising from poor disease management and complications of existing conditions from costs related to new health conditions. In tandem with this work, the duration of individuals' exposures to food insecurity needs to be tracked beyond the 12-month window captured in the Canadian Community Health Survey.

Our study used data from 2005-2010, but the prevalence of household food insecurity in Ontario has not changed significantly in recent years. ${ }^{1}$ Furthermore, Ontario has one of the lowest rates of food insecurity in Canada, at $11.7 \%$ in 2012. ${ }^{1}$ Thus, food insecurity is likely taking an even greater toll on provincial and territorial health care budgets elsewhere in Canada.

\section{Conclusion}

Our study showed that household food insecurity was a robust predictor of health care utilization and costs incurred by working-age adults, independent of other social determinants of health. Policy interventions at the provincial or federal level designed to reduce household food insecurity could offset considerable public expenditures in health care and improve overall health.

\section{References}

1. Tarasuk V, Mitchell A, Dachner N. Household food insecurity in Canada, 2012. Toronto: Research to Identify Policy Options to Reduce Food Insecurity (PROOF); 2014.

2. Gundersen C, Kreider B. Bounding the effects of food insecurity on children's health outcomes. J Health Econ 2009;28:971-83.

3. Cook JT, Frank DA, Berkowitz C, et al. Food insecurity is associated with adverse health outcomes among human infants and toddlers. J Nutr 2004; 134:1432-8.

4. Cook JT, Frank DA, Levenson S, et al. Child food insecurity increases risks posed by household food insecurity to young children's health. J Nutr 2006;136:1073-6. 
5. McIntyre L, Connor SK, Warren J. Child hunger in Canada: results of the 1994 National Longitudinal Survey of Children and Youth. CMAJ 2000;163:961-5.

6. Ryu JH, Bartfeld J. Household food insecurity during childhood and subsequent health status: the Early Childhood Longitudinal Study — kindergarten cohort. Am J Public Health 2012;102:e50.

7. Kirkpatrick SI, McIntyre L, Potestio M. Child hunger and longterm adverse consequences for health. Arch Pediatr Adolesc Med 2010;164:754-62.

8. McIntyre L, Williams J, Lavorato D, et al. Depression and suicide ideation in late adolescence and early adulthood are an outcome of child hunger. J Affect Disord 2013;150:123-9.

9. Heflin CM, Siefert K, Williams DR. Food insufficiency and women's mental health: findings from a 3-year panel of welfare recipients. Soc Sci Med 2005;61:1971-82.

10. Seligman HK, Laraia BA, Kushel MB. Food insecurity is associated with chronic disease among low-income NHANES participants. J Nutr 2010;140:304-10

11. Tarasuk V, Mitchell A, McLaren L, et al. Chronic physical and mental health conditions among adults may increase vulnerability to household food insecurity. J Nutr 2013;143:1785-93.

12. Seligman HK, Bindman AB, Vittinghoff E, et al. Food insecurity is associated with diabetes mellitus: results from the National Health Examination and Nutrition Examination Survey (NHANES) 1999-2002. J Gen Intern Med 2007;22:1018-23.

13. Muldoon KA, Duff P, Fielden S, et al. Food insufficiency is associated with psychiatric morbidity in a nationally representative study of mental illness among food insecure Canadians. Soc Psychiatry Psychiatr Epidemiol 2013;48:795-803.

14. Whitaker RC, Phillips SM, Orzol SM. Food insecurity and the risks of depression and anxiety in mothers and behavior problems in their preschool-aged children. Pediatrics 2006;118:e859-68.

15. Nakhaie R, Arnold R. A four year (1996-2000) analysis of social capital and health status in Canada: the difference that love makes. Soc Sci Med 2010;71:1037-44.

16. Nelson K, Cunningham W, Andersen R, et al. Is food insufficiency associated with health status and health care utilization among adults with diabetes? J Gen Intern Med 2001;16:404-11.

17. Anema A, Chan K, Weiser S, et al. Relationship between food insecurity and mortality among HIV-positive injection drug users receiving antiretroviral therapy in British Columbia, Canada. PLOS ONE 2013;8:e61277.

18. Seligman HK, Davis T, Schillinger D, et al. Food insecurity is associated with hypoglycemia and poor diabetes self-management in a low-income sample with diabetes. $J$ Health Care Poor Under served 2010;21:1227-33.

19. Fitzpatrick T, Rosella LC, Calzavara A, et al. Looking beyond income and education: socioeconomic status gradients among future high-cost users of health care. Am J Prev Med 2015; pii:S0749-3797(15)00082-3.

20. Ford ES. Food security and cardiovascular disease risk among adults in the United States: findings from the National Health and Nutrition Examination Survey, 2003-2008. Prev Chronic Dis 2013;10:E202.

21. Normén L, Chan K, Braitstein P, et al. Food insecurity and hunger are prevalent among HIV-positive individuals in British Columbia, Canada. J Nutr 2005;135:820-5.

22. Parker ED, Widome R, Nettleton J, et al. Food security and metabolic syndrome in US adults and adolescents: findings from the National Health and Nutrition Examination Survey, 1996-2006. Ann Epidemiol 2010;20:364-70.

23. Tayie FA, Zizza C. Food insecurity and dyslipidemia among adults in the United States. Prev Med 2009;48:480-5.

24. Anema A, Vogenthaler N, Frongillo EA, et al. Food insecurity and HIV/AIDS: current knowledge, gaps, and research priorities. Curr HIV/AIDS Rep 2009;6:224-31.

25. Bhargava V, Lee JS, Jain R, et al. Food insecurity is negatively associated with home helath and out-of-pocket expenditures in older adults. $J$ Nutr 2012;142:1888-95.

26. Canadian Community Health Survey - annual component (CCHS): detailed information for 2008. Ottawa: Statistics Canada; 2009.

27. Canadian Community Health Survey (CCHS): detailed information for 2005 (cycle 3.1). Ottawa: Statistics Canada; 2007.

28. Canadian Community Health Survey - annual component (CCHS): detailed information for 2007 (cycle 4.1). Ottawa: Statistics Canada; 2008

29. Canadian Community Health Survey - annual component (CCHS): detailed information for 2010. Ottawa: Statistics Canada; 2013.

30. Mustard CA, Derkson S, Berthelot J, et al. Assessing ecologic proxies for household income: a comparison of household and neighbourhood level income measures in the study of population health status. Health Place 1999;5:157-71.
31. Bickel G, Nord M, Price C, et al. Guide to measuring household food security. Alexandria (VA): US Department of Agriculture, Food and Nutrition Service, Office of Analysis, Nutrition and Evaluation; 2000

32. Canadian Community Health Survey, cycle 2.2, nutrition (2004): income-related household food security in Canada [report no. 4696]. Ottawa: Health Canada; 2007.

33. Loopstra R, Tarasuk V. What does increasing severity of food insecurity indicate for food insecure families? Relationship between severity of food insecurity and indicators of matrial hardship and constrained food purchasing. J Hunger Environ Nutr 2013;8:337-49.

34. Coleman-Jensen AUS. Food insecurity status: toward a refined definition. Soc Indic Res 2010;95:215-30.

35. Laraia BA, Siega-Riz AM, Gundersen C, et al. Psychosocial factors and socioeconomic indicators are associated with household food insecurity among pregnant women. $J$ Nutr 2006;136:177-82.

36. Wodchis W, Bushmeneva K, Nikitovic M, et al. Guidelines on person-level costing using administrative databases in Ontario [Working Paper series, vol. 1]. Toronto: Health System Performance Research Network; 2013.

37. Buntin MB, Zaslavsky A. Too much ado about two-part models and transformation? Comparing methods of modeling Medicare expenditures. J Health Econ 2004;23:525-42.

38. Manning WG, Mullahy J. Estimating log models: To transform or not to transform? J Health Econ 2001;20:461-94.

39. Duan N. Smearing estimate: a nonparametric retransformation method. J Am Stat Assoc 1983;78:605-10.

40. The Ontario Drug Benefit (ODB) program. Toronto: Ontario Ministry of Health and Long-Term Care. Available: www.health.gov. on.ca/en/public/programs/drugs/programs/odb/odb.aspx (modified 2015 Feb. 3; accessed 2015 June 30).

41. Marjerrison S, Cummings E, Glanville NT, et al. Prevalence and associations of food insecurity in children with diabetes mellitus. J Pediatr 2011;158:607-11.

42. Hamelin AM, Mercier C, Bedard A. Perceptions of needs and responses in food security: divergence between households and stakeholders. Public Health Nutr 2008;11:1389-96.

43. Loopstra R, Tarasuk V. Perspectives on community gardens, community kitchens and the Good Food Box program in a communitybased sample of low income families. Can J Public Health 2013;104:e55-9.

44. Loopstra R, Tarasuk V. The relationship between food banks and household food insecurity among low-income Toronto families. Can Public Policy 2012;38:497-514.

45. Tarasuk V, Dachner N, Hamelin AM, et al. A survey of food bank operations in five Canadian cities. BMC Public Health 2014; $14: 1234$

46. Loopstra R, Tarasuk V. Severity of household food insecurity is sensitive to change in household income and employment status among low-income families. J Nutr 2013;143:1316-23.

47. McIntyre L. Food security: more than a determinant of health Policy Options 2003;24:46-51.

48. Ionescu-Ittu R, Glymour M, Kaufman J. A difference-in-difference approach to estimate the effect of income-supplementation on food insecurity. Prev Med 2015;70:108-16.

49. Emery JH, Fleisch V, McIntyre L. How a guaranteed annual income could put food banks out of business. SPP Res Papers 2013;6:1-20.

50. Emery JC, Fleisch V, McIntyre L. Legislated changes to federal pension income in Canada will adversely affect low income seniors' health. Prev Med 2013;57:963-6.

51. Tarasuk V, McIntyre L, Li J. Low-income women's dietary intakes are sensitive to the depletion of household resources in one month. J Nutr 2007;137:1980-7.

52. Kirkpatrick SI, Tarasuk V. Food insecurity is associated with nutrient inadequacies among Canadian adults and adolescents. J Nutr 2008; 138:604-12.

53. Dixon LB, Winkleby MA, Radimer KL. Dietary intakes and serum nutrients differ between adults from food-insufficient and food-sufficient families: Third National Health and Nutrition Examination Survey, 1988-1994. J Nutr 2001;131:1232-46.

54. Hamelin AM, Beaudry M, Habicht JP. Characterization of household food insecurity in Quebec: food and feelings. Soc Sci Med 2002;54:119-32.

55. Kushel MB, Gupta R, Gee L, et al. Housing instability and food insecurity as barriers to health care among low-income Americans. J Gen Intern Med 2006;21:71-7.

56. Muirhead V, Quinonez C, Figueriredo R, et al. Oral health disparities and food insecurity in working poor Canadians. Community Dent Oral Epidemiol 2009;37:294-304.

57. Nielsen R, Garasky S, Chatterjee S. Food insecurity and out-ofpocket medical expenditures: Competing basic needs? Fam Consum Sci Res J 2010;39:137-51. 
58. McIntyre L, Bartoo A, Emery J. When working is not enough: food insecurity in the Canadian labour force. Public Health Nutr 2014:17:49-57.

59. McLeod L, Veall M. The dynamics of food insecurity and overall health: evidence from the Canadian National Population Health Survey. Appl Econ 2006;38:2131-46.

60. Heflin CM, Corcoran ME, Siefert K. Work trajectories, income changes, and food sufficiency in a Michigan welfare population. Soc Serv Rev 2007; (March):3-25.

61. Huang J, Guo B, Kim Y. Food insecurity and disability: Do economic resources matter? Soc Sci Res 2010;39:111-24.

Affiliations: Department of Nutritional Sciences, University of Toronto (Tarasuk, Dachner); Centre for Addiction and Mental Health (Cheng, de Oliveira, Kurdyak); Institute for Clinical and Evaluative Sciences (Cheng, Kurdyak); Institute for Health Policy, Management and Evaluation, University of Toronto (de Oliveira, Kurdyak), Toronto, Ont.; Department of Agricultural and Consumer Economics, University of Illinois (Gundersen), Urbana, Ill.

Contributors: Valerie Tarasuk conceived of the study and oversaw all aspects of it. Joyce Cheng conducted the statistical analyses, with guidance from Claire de Oliveira, Craig
Gundersen and Paul Kurdyak. Valerie Tarasuk, Joyce Cheng, Claire de Oliveira, Naomi Dachner and Craig Gundersen were responsible for the interpretation of the analytic results. Paul Kurdyak facilitated access to the data. Valerie Tarasuk, Joyce Cheng and Naomi Dachner drafted the manuscript. All of the authors contributed to the critical revision of the manuscript, approved the final version to be published and agreed to act as guarantors of the work.

Funding: This study was funded by a Programmatic Grant in Health and Health Equity from the Canadian Institutes of Health Research (CIHR) (grant no. FRN 115208). The analysis was also supported by the Institute for Clinical Evaluative Sciences (ICES), which is funded by an annual grant from the Ontario Ministry of Health and Long-Term Care (MOHLTC). The opinions, results and conclusions reported in this paper are those of the authors and are independent from the funding sources. No endorsement by the CIHR, ICES or the MOHLTC is intended or should be inferred. The study sponsors had no role in the design of the study, the collection, analysis or interpretation of data, the writing of the report or the decision to submit the article for publication. 